\title{
An Insight into Induced Seismicity in Bangladesh: A Statistical Analysis Approach
}

\author{
Mohammad Ahsan Uddin* \\ Associate Professor, Department of Statistics, University of Dhaka, Dhaka, Bangladesh
}

DOI: $\underline{\text { 10.36348/sjet.2020.v05i12.003 }}$ | Received: 27.11 .2020 | Accepted: 09.12 .2020 | Published: 14.12 .2020

*Corresponding author: Mohammad Ahsan Uddin

\section{Abstract}

Bangladesh is used to struggle with several natural disasters and has become one of the most earthquake vulnerable countries of the world. The nature and the distribution of the earthquake events in different seismic zones of Bangladesh are related to various man-made factors. This study is dealing with the impact of these factors which are leading to the incidence of earthquakes. Geographic information system (GIS) is used to analyze earthquake data graphically. Bivariate analysis is conducted using t-test approach for hypothesis testing purpose. Availability of gas and oil has been turned out as significant in the results on earthquake occurrences. Three Poisson regression models, along with bivariate analysis, are employed in this study to assess the occurrence of earthquakes in relation with having minerals in Bangladesh. The results give evidence that the presence of minerals is vulnerable to earthquake and production of minerals increases the vulnerability. The presence of gas and oil in the related districts significantly increases the expected number of earthquakes. Keeping similarity with this result, the districts where gas and oil production are running also experience significantly more frequency of earthquakes compared to that of other districts. It is also found from the analysis that the more amount of gas the districts have, the higher the expected number of earthquakes is in that districts. However, neither presence of coal nor running of coal production has any significant effect on earthquake occurrence.

Keywords: Earthquake, geographic information system (GIS), t-test, Poisson regression.

Copyright $\odot 2020$ The Author(s): This is an open-access article distributed under the terms of the Creative Commons Attribution 4.0 International License (CC BY-NC 4.0) which permits unrestricted use, distribution, and reproduction in any medium for non-commercial use provided the original author and source are credited.

\section{INTRODUCTION}

Earthquake is the measurable vibration of the Earth's crust which is caused by abrupt transient movement along faults [1]. An earthquake is caused by a sudden slip on a fault. The tectonic plates are always slowly moving, but they get stuck at their edges due to friction. When the stress on the edge overcomes the friction, there is an earthquake that releases energy in waves that travel through the earth's crust and cause the shaking that we feel. It is one of the deadliest natural disasters that affects the human environment [2]. Even a moderate earthquake can cause a very large number of deaths [3].

Induced seismicity refers to typically minor earthquakes and tremors that are caused by human activity that alters the stresses and strains on the Earth's crust. While these quakes, now called induced seismicity, are mostly minor, in many cases they turn out to have a considerable damage and/or intensify or provoke naturally occurring earthquakes by advancing the natural timeline. Researchers from the United States, the United Kingdom, and Switzerland, among others, have irrefutably established the connection [4]. 


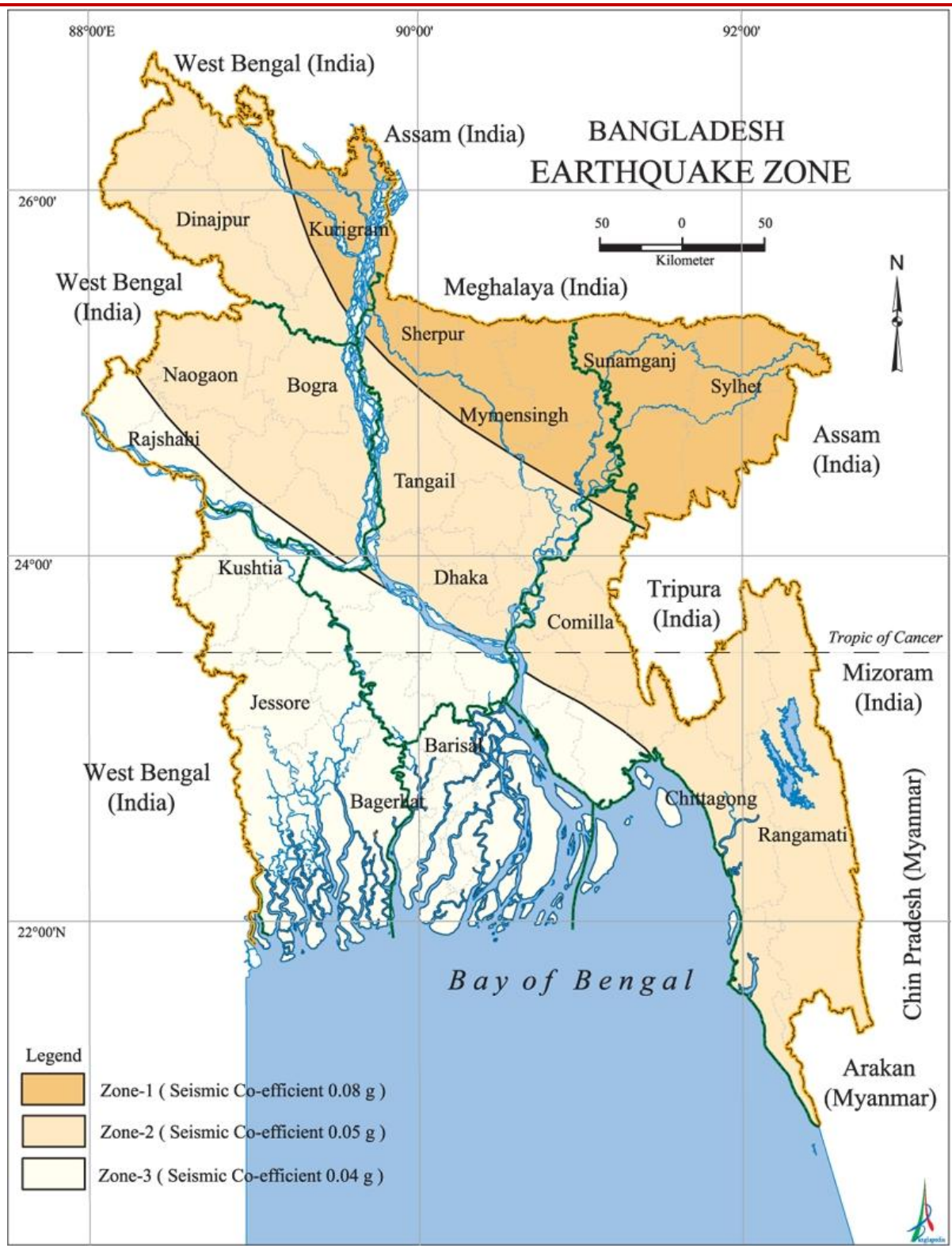

Fig-1: Bangladesh Earthquake Zones

(Source: Banglapedia, 2015)

This study is concerned with the events of induced earthquakes in Bangladesh. The adjoining areas and tectonic framework of Bangladesh tell that Bangladesh is located adjacent to the plate margins of India and Eurasia where, in the past, demolishing earthquakes have occurred [5]. Our country is encompassed by a number of tectonic blocks that have produced earthquakes in recent times [6]. But, the new Bangladeshi generation hasn't found any destructive earthquake [7]. As a result, there is lack of awareness about the dangerous effects of earthquake among the Bangladeshi people [5]. As concerned, Bangladesh is a densely populated country, even a minor seismic activity can have a drastic impact affecting comparatively more people causing greater loss [8]. For instance, if a tremor is felt even in a small area causing damage to its streets, industries etc., many people will be affected, compared to that of a small city. Therefore, it is worth researching whether we are putting ourselves in danger by artificially introducing factors that can cause, intensify or advance seismicity. And if the connection is established, proper steps must be taken immediately to avert loss of lives as well as wealth.

The probability of an earthquake from a given fault depends on the rate of motion and on the time since the last rupture. Active faults of regional scale capable of generating moderate to great earthquakes are present in and around Bangladesh. There is a connection between the events of earthquake and the human activities as evident from a number of researches conducted through last few decades [9]. Induced earthquakes have been linked with mining of gas, coal, and oil; waste disposal wells; groundwater extraction; artificial lakes; hydrocarbon extraction and storage; geothermal energy; hydraulic fracturing; and carbon 
capture, and storage, the first few cases being well prevalent in Bangladesh. A statistical investigation is conducted in this study to find out the possible association between these human activities and the event of earthquakes in Bangladesh. The study aims to detect the most influential factors and mechanism leading to induced seismicity in Bangladesh. Also, the study attempts to find out the regions that are most vulnerable because of such activities using geographic information system (GIS).

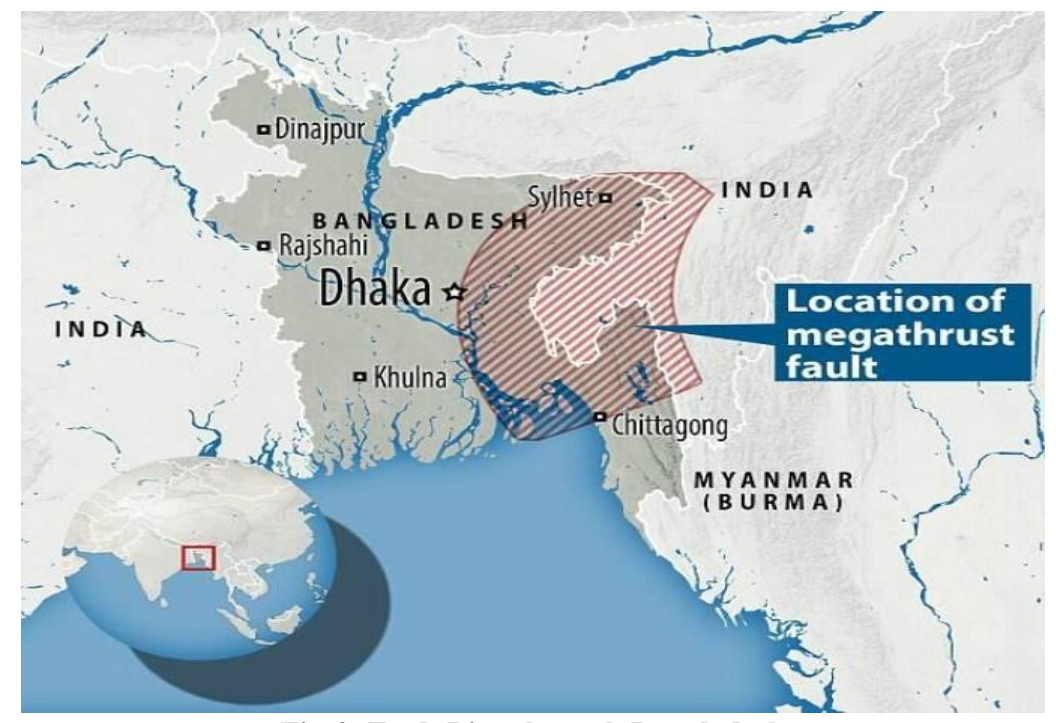

Fig-2: Fault Line through Bangladesh

(Source: The Daily Mail, 22 July 2016)

\section{METHODS AND MATERIALS}

This study is totally based on secondary data. The target population of this study can be dealt with from multiple perspectives. Firstly, data concerning all earthquakes occurred in Bangladesh are needed i.e., earthquakes that had their epicenters in Bangladesh. Secondly, data about which regions in Bangladesh have mineral resources are sought. Then, data are needed on which mineral resources are available, and lastly, on from which regions mineral resources are actively produced and since when. The study area of this study is concerned with all Bangladeshi districts. Then, after getting the earthquakes and production data, the study deals with only those regions concerned with either of these data. The variables concerned are, number of earthquakes per year, type of earthquake, class of earthquakes, number of earthquakes per district, presence or absence of various mineral resources, production status of mineral resources, starting year of production of resources, and amount of production. The data sources can be summarized as follows:

Table-1: Sources of Data

\begin{tabular}{|l|l|}
\hline Purpose & Source \\
\hline Earthquake Data & United States Geological Survey \\
\hline Earthquake Data & $\begin{array}{l}\text { Earthquake Track } \\
\text { Web: www.earthquaketract.com }\end{array}$ \\
\hline Earthquake Data & $\begin{array}{l}\text { University of California, Berkeley } \\
\text { Web: http://quake.geo.berkeley.edu/anss/catalog-search.html }\end{array}$ \\
\hline Production Data & $\begin{array}{l}\text { Petrobangla } \\
\text { Web: www.petrobangla.org.bd }\end{array}$ \\
\hline Production Data & $\begin{array}{l}\text { Bapex } \\
\text { Web: www.bapex.com.bd }\end{array}$ \\
\hline Production Data & Banglapedia Bengali and English Version \\
\hline Production Data & $\begin{array}{l}\text { Sylhet Gas Fields Limited } \\
\text { Web: sgfl.org.bd }\end{array}$ \\
\hline Production Data & $\begin{array}{l}\text { Bangladesh Geological Survey } \\
\text { Web: bsb.gov.bd }\end{array}$ \\
\hline
\end{tabular}

This study incorporates geographic information system (GIS) which is designed to analyze and present geographic data [10]. Bivariate analysis is conducted to determine whether a statistical association exists between two interested variables which provides the nature, direction and strength of that relationship [11]. Bivariate analysis can be performed through a number of ways depending on the nature of available 
data. This study performs t-test to test the relevant hypothesis as a means of bivariate analysis. Regression analysis, a very common form of statistical analysis approach, is used as the main analytical tool [12]. This analysis is concerned with the relationship between a dependent variable and one or more independent variables [13]. It helps one understand how the value of the response variable changes for any one of the independent variables is varied, keeping other independent variables constant [14]. There are several forms of regression analysis according to the type of data. This paper considers Poisson regression, which is a popular method used to predict a dependent variable which consists of 'count data' given one or more independent variables [15]. Poisson regression assumes the dependent variable $\mathrm{Y}$ follows Poisson distribution and the logarithm of the expected value of the response variable can be modeled by a linear combination of unknown parameters [16]. If $\mathrm{Y}$ be the dependent variable and $\mathbf{x}$ be the vector of independent variables, then the Poisson regression takes the form as: $\log (\mathrm{E}(\mathrm{Y} \mid \mathrm{X}))=\alpha+\beta^{\prime} \mathrm{x}$,
Where $\alpha$ is the intercept term and $\boldsymbol{\beta}$ be the vector of regression parameters [17]. To predict future values of a variable based on its previously observed values, time series forecasting model is used. This study considers advanced time series modeling approach in which various time series processes like autoregressive (AR) process, moving average (MA) process are used. These processes consider the lag values of the dependent variables and white noises for modeling purpose [18-20].

\section{RESULTS \& DISCUSSIONS}

GIS techniques can be performed through R, exactly what is done in this geo-analysis part. From Figure-3, it is easy to find out the areas that experienced at least one earthquake, marked by the different colors. While the lime green color shows the districts with no earthquakes ever. It can be concluded that, most of the districst in Bangladesh have not experienced any earthquake as yet. Figure reveals that the Cox's Bazar district encountered the maximum number of earthquakes [21], followed by four districts including Sylhet and Chittagong.

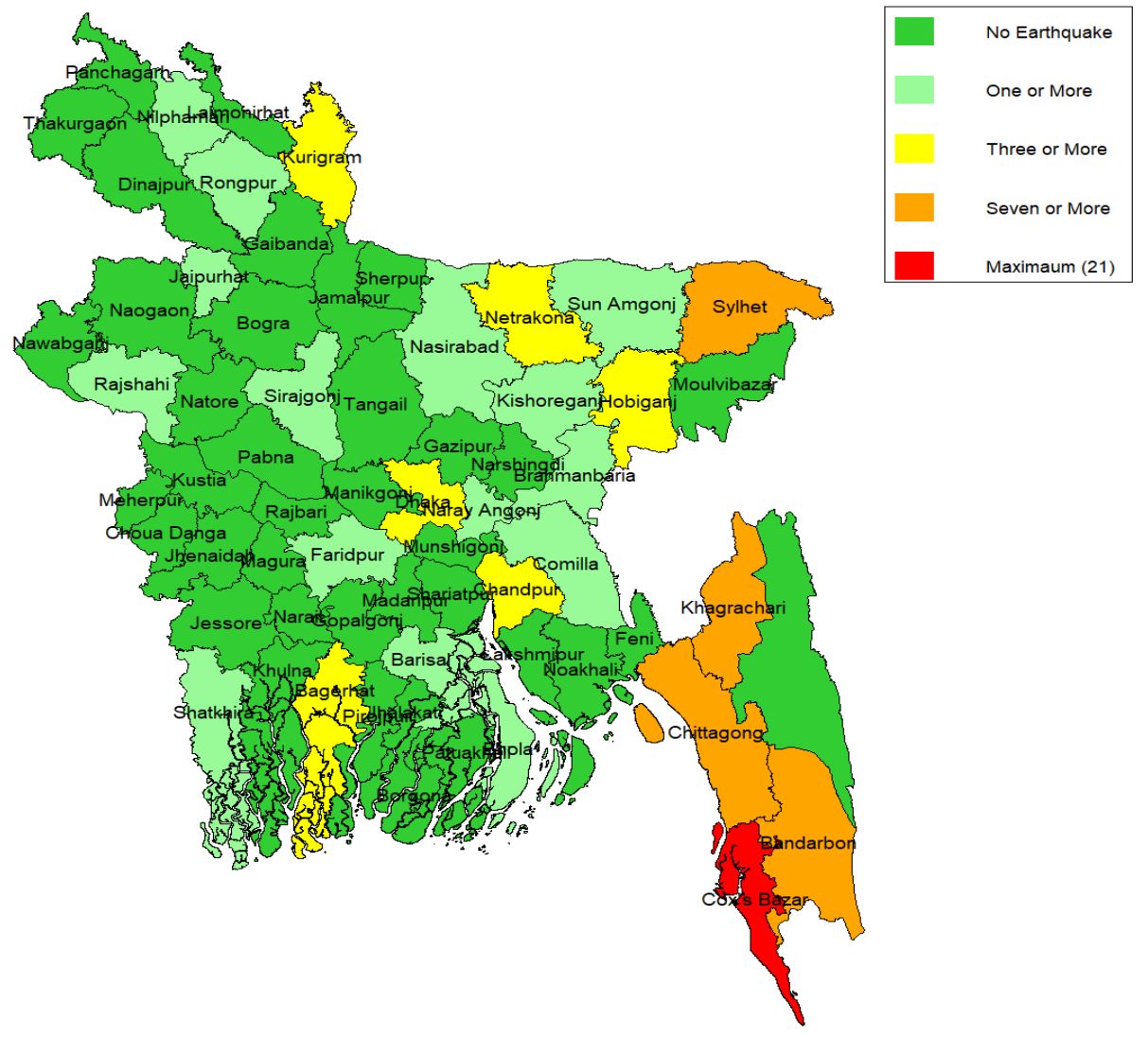

Fig-3: Bangladesh Map showing the frequencies of earthquakes in each district

The line chart (Figure-4) says that the earthquakes were less frequent before 1970s. However, after 1970s, the number of earthquakes dramatically increased continuing up to present time. Earthquakes in
Bangladesh started in the year 1918, which saw one quake. The next quake occurred in five years later (1923). But it took more than 30 years for the next earthquake to occur. Up to 1963 , there were, in total, six 
earthquakes. The 1979 was the first to see more than two quakes. After that, it became to have more than one earthquake in a single calendar year. For example, there were three earthquakes in 1988, two in the next years, five in 1991, four in 1992 etc. The line chart also says that the frequency of earthquakes in recent years is also more than three. This study is intrigued to analyze the pattern of magnitude of earthquakes before and after 1963, a year shortly before which (in 1961), production of mineral resources began.

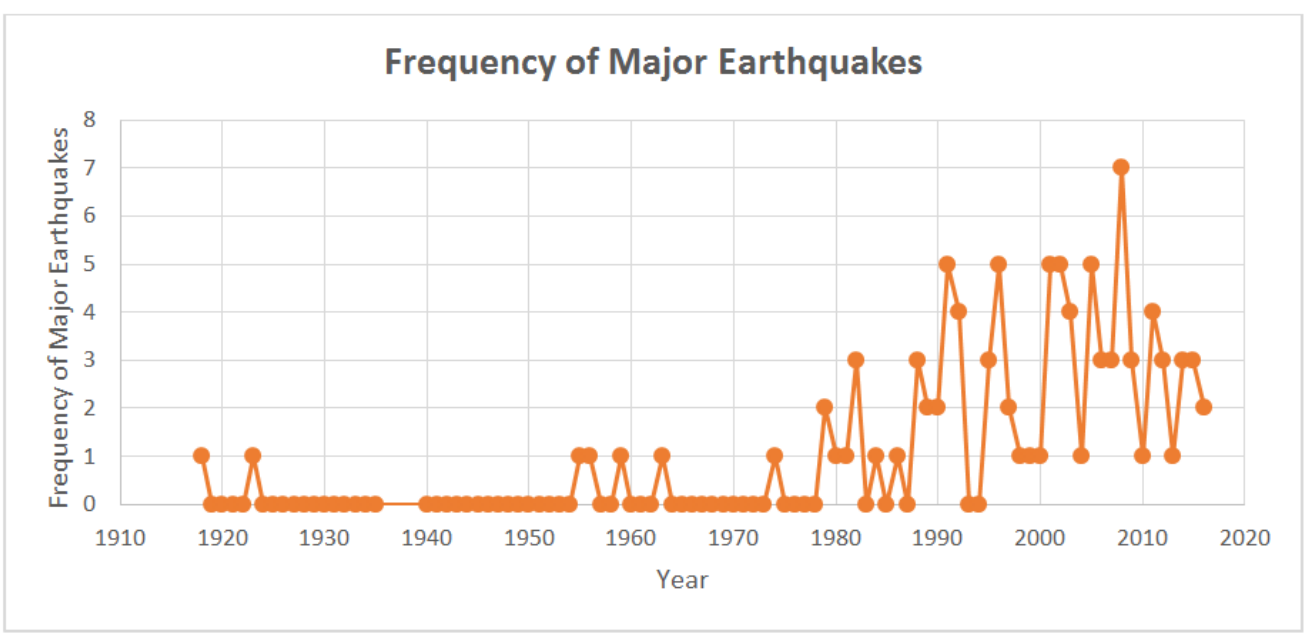

Fig-4: Frequency of Major earthquakes in Bangladesh (1918-2016)

A quick look on Table-2 reveals the fact that the earthquakes that occurred before or in 1953 were of relatively greater magnitude, each of which were no less than 5.5 magnitudes. However, the earthquakes that occurred after the year 1963 were all below 5.5 except one (in 2003). This clearly indicates that production of mineral resources contributed to the relatively minor quakes which were at the same time much more frequent. The earthquake occurred in 2003 can be considered to probably have happened due to natural causes. But, we can attribute others to the production process.

Table-2: List of earthquakes in Bangladesh along with occurring year

\begin{tabular}{|l|l|l|l|l|l|l|l|}
\hline Year & Magnitude & Year & Magnitude & Year & Magnitude & Year & Magnitude \\
\hline 2016 & 4.4 & 2008 & 4.2 & 2001 & 3.8 & 1990 & 3.8 \\
\hline 2016 & 4.7 & 2008 & 3.8 & 2001 & 4.3 & 1990 & 4 \\
\hline 2015 & 4 & 2007 & 5.5 & 2001 & 4.1 & 1989 & 5.8 \\
\hline 2015 & 4.2 & 2007 & 3.5 & 2000 & 4.7 & 1989 & 4.1 \\
\hline 2015 & 4.6 & 2007 & 4.8 & 1999 & 5.2 & 1988 & 4.6 \\
\hline 2014 & 4.2 & 2006 & 4.2 & 1998 & 4 & 1988 & 4.5 \\
\hline 2014 & 4.3 & 2006 & 4.9 & 1997 & 4.8 & 1988 & 5.9 \\
\hline 2014 & 4.2 & 2006 & 3.6 & 1997 & 4.1 & 1986 & 4.7 \\
\hline 2013 & 4.1 & 2005 & 4 & 1996 & 3.8 & 1984 & 4.4 \\
\hline 2012 & 4.2 & 2005 & 4.2 & 1996 & 4.2 & 1982 & 4.6 \\
\hline 2012 & 4.2 & 2005 & 4.6 & 1996 & 3.9 & 1982 & 4.2 \\
\hline 2012 & 4.5 & 2005 & 4.4 & 1996 & 4.1 & 1982 & 4.7 \\
\hline 2011 & 4.2 & 2005 & 4.3 & 1996 & 4.7 & 1981 & 4.2 \\
\hline 2011 & 4.4 & 2004 & 4.3 & 1995 & 4.1 & 1980 & 4.6 \\
\hline 2011 & 4.7 & 2003 & 4.2 & 1995 & 4.3 & 1979 & 4.8 \\
\hline 2011 & 4.1 & 2003 & 4.3 & 1995 & 3.8 & 1979 & 4.9 \\
\hline 2010 & 5.1 & 2003 & 4.3 & 1992 & 4.1 & 1974 & 5 \\
\hline 2009 & 4.9 & 2003 & 5.7 & 1992 & 5.3 & 1963 & 5.6 \\
\hline 2009 & 4.6 & 2002 & 3.9 & 1992 & 4.5 & 1955 & 6.2 \\
\hline 2009 & 4.1 & 2002 & 4.9 & 1992 & 4.2 & 1956 & 5.5 \\
\hline 2008 & 4.1 & 2002 & 4.5 & 1991 & 4.6 & 1959 & 5.7 \\
\hline 2008 & 4.2 & 2002 & 4.5 & 1991 & 4.7 & 1923 & 6.8 \\
\hline 2008 & 4.5 & 2002 & 4.1 & 1991 & 4.7 & 1918 & 7.2 \\
\hline 2008 & 4.7 & 2001 & 4.5 & 1991 & 4.7 & & \\
\hline 2008 & 4.8 & 2001 & 3.5 & 1991 & 4 & & \\
\hline
\end{tabular}

The foregoing result can also be derived by employing a t-test of comparing means. The hypothesis to be tested here is

$$
\begin{aligned}
& \mathrm{H}_{0}: \mu_{1}=\mu_{2} \\
& \mathrm{H}_{1}: \mu_{1} \neq \mu_{2}
\end{aligned}
$$




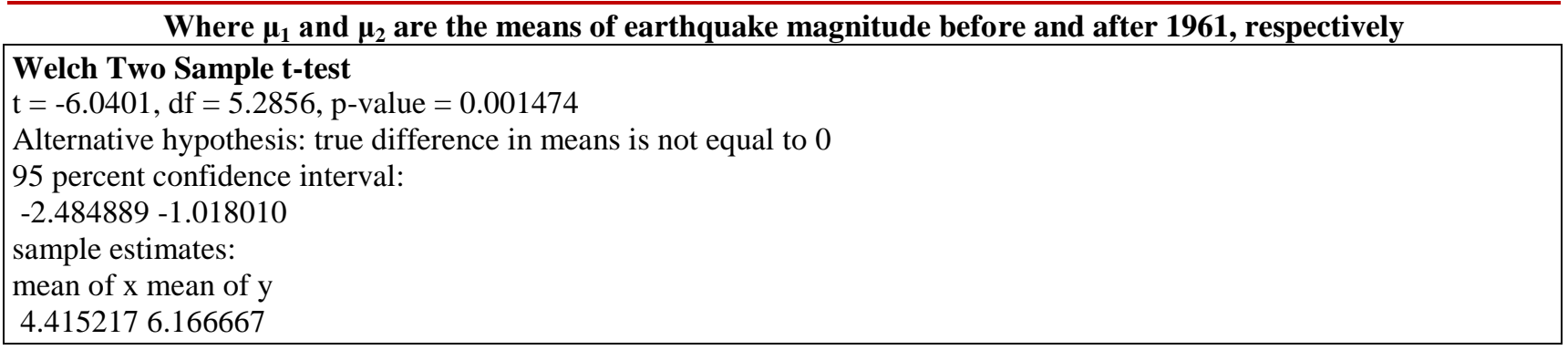

Since the p-value is smaller than 0.01 , the null hypothesis may be rejected at $1 \%$ significance level giving enough evidence to claim that the mean magnitudes of earthquakes before and after 1961 are not equal. Usually the naturally occurring earthquakes have higher magnitudes than those resulting from artificial reasons. Hence, the significant difference in the magnitude indicates that the production process contributed to seismic activities.
The Figure-5 clearly shows that in most of the districts the number of earthquakes after the start of mineral production is more than before the start of mineral production except for the district Khagrachari. This may be an effect of the mineral production in Chittagong. So, it can be said that there may be an effect of mineral production on the event of earthquake.

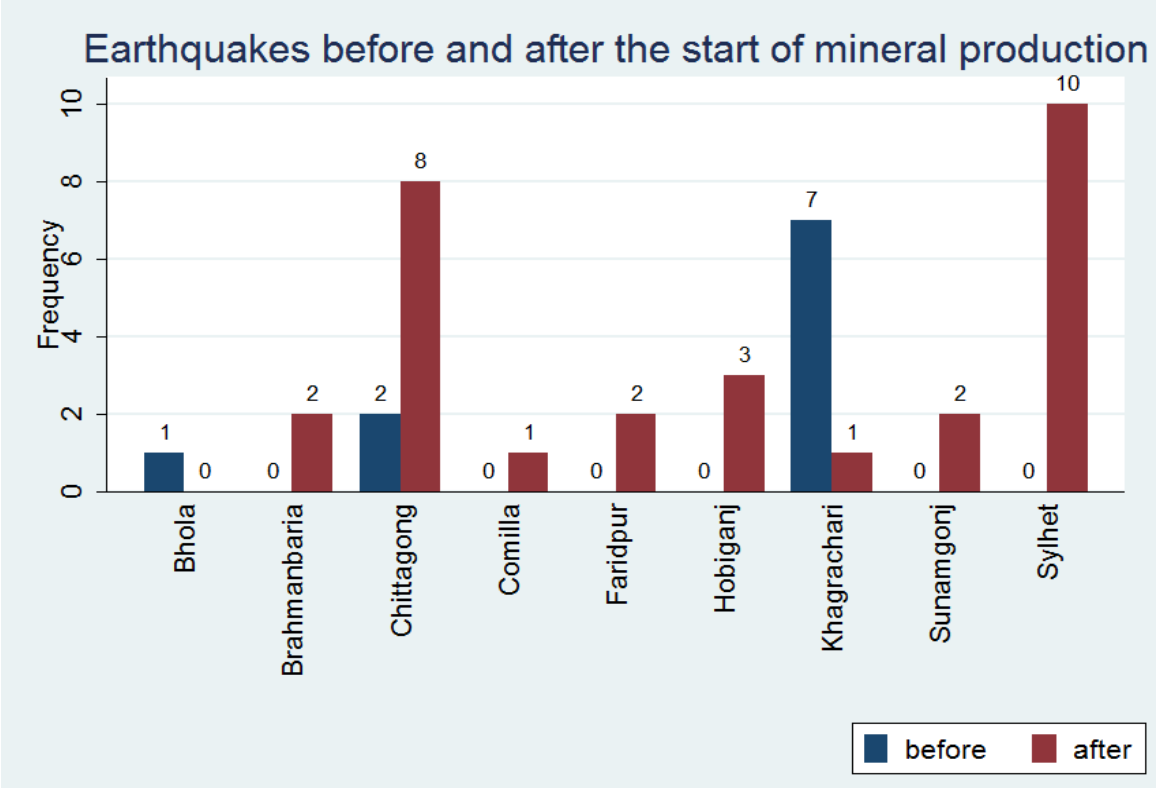

Fig-5: District wise earthquakes before and after the start of mineral production

The number of earthquakes in different districts of Bangladesh having gas, coal, and oil is being modeled through Poisson regression model and the obtained results are shown in Table-3. The result shows that presence of gas and oil is significantly related to the number of earthquake occurrence while presence of coal is not. The expected number of earthquakes in the districts where gas is available is 4.517 times the districts where gas is not available, when no other mineral is available. This result is significant at $1 \%$ significance level with p-value less than 0.001 . Presence of oil is also significant (p-value 0.060) in the model at $10 \%$ level of significance. The expected number of earthquakes is 3.689 times higher in the districts where oil is available compared to the districts where oil is not available, when there is no other mineral available.
Table-3: Poisson regression model estimates of the selected covariates along with standard error (SE) and p-value for number of earthquakes concerned with the presence of minerals

\begin{tabular}{|c|c|c|c|}
\hline Covariates & Coefficient & SE & p-value \\
\hline Gas & & & \\
\hline Available & 4.517 & 0.978 & $<0.001$ \\
\hline Unavailable & - & - & - \\
\hline Oil & & & \\
\hline Available & 3.689 & 2.556 & 0.060 \\
\hline Unavailable & - & - & - \\
\hline Coal & & & \\
\hline Available & 0.625 & 0.372 & 0.431 \\
\hline Unavailable & - & - & - \\
\hline Constant & 0.959 & 0.139 & 0.775 \\
\hline \multicolumn{4}{|r}{}
\end{tabular}


Mohammad Ahsan Uddin; Saudi J Eng Technol, Dec, 2020; 5(12): 501-508

Table-4 is showing the Poisson regression estimates to number of earthquakes in the districts where gas, oil, and coal production is running. Similar to the previous result, the districts where coal production is running have no significant association with earthquake occurrence. The districts where gas production is running are significantly experiencing earthquakes at $5 \%$ level of significance with p-value 0.017 . The expected number of earthquakes in these districts is 1.747 times the districts where gas production is not running, ensuring no other mineral production is running. Again, in the districts where oil production is running have significantly ( $p$-value $<0.001) 4.615$ times more expected number of earthquakes than that of the districts where oil production is not running, ensuring no other mineral production is running.
Table-4: Poisson regression model estimates of the selected covariates along with standard error (SE) and p-value for number of earthquakes concerned with the running of mineral production

\begin{tabular}{|l|l|l|l|}
\hline Covariates & Coefficient & SE & p-value \\
\hline Gas production & & & \\
\hline Available & 1.747 & 0.408 & 0.017 \\
\hline Unavailable & - & - & - \\
\hline Oil production & & & \\
\hline Available & 4.615 & 1.717 & $<0.001$ \\
\hline Unavailable & - & - & - \\
\hline Coal production & & & \\
\hline Available & 0.806 & 0.812 & 0.831 \\
\hline Unavailable & - & - & - \\
\hline Constant & 1.240 & 0.157 & 0.090 \\
\hline
\end{tabular}

Table-5 is depicting how the amount of gas production is related to number of earthquakes. The amount of daily gas production is insignificant in the model. But, if the amount of total gas production increases 1 bcf (billion per cubic feet), expected number of earthquakes is significantly 1.001 times the previous number of earthquakes having p-value 0.010, holding the amount of daily production constant.

Table-5: Poisson regression model estimates of the selected covariates along with standard error (SE) and p-value for number of earthquakes concerned with amount of gas production

\begin{tabular}{|l|l|l|l|}
\hline Covariates & Coefficient & SE & p-value \\
\hline Daily gas production & 0.997 & 0.001 & 0.172 \\
\hline Total gas production & 1.001 & $<0.001$ & 0.010 \\
\hline Constant & 1.434 & 0.154 & 0.001 \\
\hline
\end{tabular}

The GIS technique detects the districts which have had at least one earthquake and finds most of the districst in Bangladesh having no earhtquake yet. The Cox's Bazar district have experienced the highest number of earthquakes [21], and its nearby districts along with Sylhet district have faced at least seven or more earthquakes. Three Poisson regression models, along with bivariate analysis, are employed in this study to assess the occurrence of earthquakes in relation with having minerals in Bangladesh. The results give evidence that the presence of minerals is vulnerable to earthquake and production of minerals increases the vulnerability. The presence of gas and oil in the related districts significantly increases the expected number of earthquakes. This result is similar to some previous works on earthquakes [21-23]. Keeping similarity with this result, the districts where gas and oil production are running also experience significantly more frequency of earthquakes compared to that of other districts which is relevant to previous research findings [24]. It is also found from the analysis that the more amount of gas the districts have, the higher the expected number of earthquakes is in that districts. However, neither presence of coil nor running of coal production has any significant effect on earthquake occurrence.

\section{CONCLUSION}

The obtained analysis results conclude that induced seismicity is prevalent in Bangladesh. That is, earthquakes are caused by human-induced factors, the production of gas having the staunchest impact. The production of oil also has a significant impact on the event of earthquakes. Although, globally a number of factors (like injection of waste water, production of oil, production of hydro-carbon, artificial lakes, hydraulic fracturing, etc.) result in induced seismicity, from the perspective of Bangladesh, the gas and oil production turned out to be the only factors inducing earthquakes. The absence of other factors resulted from the fact that, although there are many other mineral resources in Bangladesh, none except gas is currently being actively produced. A thorough analysis should be conducted on the physical aspects of the association between the production of mineral resources and the event of seismicity. The research will help determine the policy concerning the production of resources. In light of the previous discussion, it is recommended to take necessary steps in the districts of Bangladesh where minerals are available to lessen the hazads of seismicity.

\section{REFERENCES}

1. Hoque, M. A., \& Aftab, A. L. A. M. (2001). Seismicity and Seismotectonic Regionalization of the Bengal Basin, Bangladesh. Bangladesh Journal of Geology, 20, 77-86.

2. Islam, M. S., Hossain, M. T., Ameen, S. F., Hoque, E., \& Ahamed, S. (2010). Earthquake 
induced liquefaction vulnerability of reclaimed areas of Dhaka. Journal of Civil Engineering (IEB), 38(1), 65-80.

3. Sharfuddin, M. (2001). Earthquake hazard analysis for Bangladesh.

4. Khan, A. A., Hoque, M., Akhter, S. H., \& Hoque, M. A. (2001). Earthquake in bangladesh: a natural disaster and public awareness. The Journal of NOAMI, 18(2), 37-46.

5. Islam, R., Islam, M. N., \& Islam, M. N. (2016). Earthquake risks in Bangladesh: causes, vulnerability, preparedness and strategies for mitigation. Arpn J Earth Sci, 5(2), 75-90.

6. Al Zaman, M. D. A., \& Monira, N. J. (2017). A Study of Earthquakes in Bangladesh and the Data Analysis of the Earthquakes that were generated In Bangladesh and Its' Very Close Regions for the Last Forty Years (1976-2016). J Geol Geophys, 6(300), 2.

7. Rabbani, M. G., \& Jabin, S. (2019). Why Bangladesh is vulnerable to earthquake?. International Journal of Perceptions in Public Health, 3(2), 27-30.

8. Jahan, I., Ansary, M. A., Ara, S., \& Islam, I. (2011). Assessing social vulnerability to earthquake hazard in Old Dhaka, Bangladesh. Asian Journal of Environment and Disaster Management (AJEDM), 3(3), 285-300.

9. Doocy, S., Daniels, A., Packer, C., Dick, A., \& Kirsch, T. D. (2013). The human impact of earthquakes: a historical review of events 19802009 and systematic literature review. PLoS currents, 5 .

10. Samet, H. (1990). The design and analysis of spatial data structures: Addison-Wesley Reading, MA; 1990.

11. Warner, R. M. (2008). Applied statistics: From bivariate through multivariate techniques. sage.

12. Draper, N. R., \& Smith, H. (1998). Applied regression analysis: John Wiley \& Sons.

13. Fox, J. (1997). Applied regression analysis, linear models, and related methods: Sage Publications, Inc.
14. Montgomery, D. C., Peck, E. A., \& Vining, G. G. (2012). Introduction to linear regression analysis (Vol. 821). John Wiley \& Sons.

15. Lawless, J. F. (1987). Negative binomial and mixed Poisson regression. The Canadian Journal of Statistics/La Revue Canadienne de Statistique, 209-225.

16. Cameron, A. C., \& Trivedi, P. K. (1990). Regression-based tests for overdispersion in the Poisson model. Journal of econometrics, 46(3), 347-364.

17. Consul, P., \& Famoye, F. (1992). Generalized Poisson regression model. Communications in Statistics-Theory and Methods, 21(1), 89-109.

18. Graupe, D., Krause, D. J., \& Moore, J. (1975). Identification of autoregressive moving-average parameters of time series. IEEE Transactions on Automatic Control, 20(1), 104-107.

19. Wang, J., \& Zhang, T. (2008, April). Degradation prediction method by use of autoregressive algorithm. In 2008 IEEE International Conference on Industrial Technology (pp. 1-6). IEEE.

20. Kapgate, D. (2014). Weighted moving average forecast model based prediction service broker algorithm for cloud computing. International Journal of Computer Science and Mobile Computing, 3(2), 71-79.

21. Khilyuk, L. F., Robertson Jr, J. O., Endres, B., \& Chilingarian, G. V. (2000). Gas migration: events preceding earthquakes. Elsevier.

22. Wu, F. T. (1975). Gas well pressure fluctuations and earthquakes. Nature. 257(5528):661-663.

23. Borfecchia, F., De Canio, G., De Cecco, L., Giocoli, A., Grauso, S., La Porta, L., ... \& Zini, A. (2016). Mapping the earthquake-induced landslide hazard around the main oil pipeline network of the Agri Valley (Basilicata, southern Italy) by means of two GIS-based modelling approaches. Natural Hazards, 81(2), 759-777.

24. Van der Voort, N., \& Vanclay, F. (2015). Social impacts of earthquakes caused by gas extraction in the Province of Groningen, The Netherlands. Environmental Impact Assessment Review, 50, 1-15. 